\title{
The Ptr1 Locus of Solanum lycopersicoides Confers Resistance to Race 1 Strains of Pseudomonas syringae pv. tomato and to Ralstonia pseudosolanacearum by Recognizing the Type III Effectors AvrRpt2 and RipBN
}

\author{
Carolina Mazo-Molina, ${ }^{1,2}$ Samantha Mainiero, ${ }^{1}$ Sarah R. Hind, ${ }^{1}$ Christine M. Kraus, ${ }^{1}$ Mishi Vachev, ${ }^{1}$ \\ Felicia Maviane-Macia, ${ }^{3}$ Magdalen Lindeberg, ${ }^{2}$ Surya Saha, ${ }^{1}$ Susan R. Strickler, ${ }^{1}$ Ari Feder, ${ }^{1}$ \\ James J. Giovannoni, ${ }^{1,4}$ Christine D. Smart, ${ }^{2}$ Nemo Peeters, ${ }^{3}$ and Gregory B. Martin ${ }^{1,2,5,+}$ \\ ${ }^{1}$ Boyce Thompson Institute for Plant Research, Ithaca, NY 14853, U.S.A. \\ ${ }^{2}$ Plant Pathology and Plant-Microbe Biology Section, School of Integrative Plant Science, Cornell University, Ithaca, NY 14853, \\ U.S.A. \\ ${ }^{3}$ LIPM, Université de Toulouse, INRA, CNRS, Castanet-Tolosan, France \\ ${ }^{4}$ Robert W. Holley Center for Agriculture and Health, USDA-ARS, Ithaca, NY 14853, U.S.A. \\ ${ }^{5}$ Department of Horticultural Biotechnology, College of Life Sciences, Kyung Hee University, Yongin 17104, Republic of Korea \\ Accepted 17 February 2019.
}

\begin{abstract}
Race 1 strains of Pseudomonas syringae pv. tomato, which cause bacterial speck disease of tomato, are becoming increasingly common and no simply inherited genetic resistance to such strains is known. We discovered that a locus in Solanum lycopersicoides, termed Pseudomonas tomato race 1 (Ptr1), confers resistance to race $1 P$. syringae pv. tomato strains by detecting the activity of type III effector AvrRpt2. In Arabidopsis, AvrRpt2 degrades the RIN4 protein, thereby activating RPS2-mediated immunity. Using site-directed mutagenesis of AvrRpt2, we found that, like RPS2, activation of Ptr1 requires AvrRpt2 proteolytic activity. Ptr1 also detected the activity of AvrRpt2 homologs from diverse bacteria, including one in Ralstonia pseudosolanacearum. The genome sequence of $S$. lycopersicoides revealed no RPS2 homolog in the Ptr1 region. Ptr1 could play an important role in controlling bacterial speck disease and its future cloning may shed light on an example of convergent evolution for recognition of a widespread type III effector.
\end{abstract}

Keywords: AvrRpt2, disease resistance, Mr5, NLR-triggered immunity, RIN4, RPS2, Solanum lycopersicum, Solanum lycopersicoides

Bacterial speck disease of tomato, caused by Pseudomonas syringae pv. tomato, occurs in cool, wet environments that

${ }^{\dagger}$ Corresponding author: G. B. Martin; gbm7@ @ cornell.edu

Funding: This work was supported by National Science Foundation (NSF) grants IOS-1546625 (to G. B. Martin) and IOS-0923312 (to J. J. Giovannoni), NSF Research Experience for Undergraduates DBI-1358843 (to M. Vachev), Laboratoire d'Excellence (LABEX), TULIP (ANR-10LABX-41 to N. Peeters and F. Maviane-Macia), and Colciencias Departamento Administrativo de Ciencia, Tecnología e Innovació grant 673 (to C. Mazo-Molina).

*The $\boldsymbol{e}$-Xtra $\operatorname{logo}$ stands for "electronic extra" and indicates that eight supplementary figures and six supplementary tables are published online.

The author(s) declare no conflict of interest.

๑ 2019 The American Phytopathological Society favor bacterial spreading and leaf colonization through stomata (Pedley and Martin 2003). Two races of P. syringae pv. tomato are currently defined, which differ in their ability to cause disease on tomato varieties expressing the resistance gene Pto. Race 0 strains express the type III effectors AvrPto or AvrPtoB, are recognized by Pto, and, consequently, are unable to cause disease on Pto-expressing tomato varieties. Race 1 strains do not have the avrPto or avrPtoB genes or do not express these effector proteins and are therefore not recognized by Pto (Kunkeaw et al. 2010; Lin et al. 2006). Recently, strains with virulence attributes intermediate between race 0 and race 1 strains have been discovered (Kraus et al. 2017). These strains express AvrPto but nevertheless multiply to levels intermediate between race 0 and race 1 strains in tomato plants that express Pto.

In order to combat pathogens, plants have evolved a twolayered immune system. In an initial defense response, plants use extracellular pattern recognition receptors to detect the presence of microbe-associated molecular patterns (Dangl et al. 2013). In the second immune response, plants use intracellular proteins (resistance [R] proteins or nucleotide-binding oligomerization domain-like receptors [NLRs]) to detect pathogen effector proteins translocated inside the host cell during the infection process. NLR-triggered immunity (NTI) is typically associated with programmed cell death and significant inhibition of pathogen multiplication (Büttner 2016; Jones and Dangl 2006).

After translocation of AvrPto or AvrPtoB into the plant cell, Pto, which is a serine and threonine protein kinase, physically interacts with either one of these effectors and acts in concert with Prf, an NLR, to activate NTI (Pedley and Martin 2003; Salmeron et al. 1996). Pto was originally identified in a wild relative of tomato, Solanum pimpinellifolium, and it has been introgressed into many processing-type tomato varieties. For over 30 years, the Pto gene has provided effective control of speck disease caused by $P$. syringae pv. tomato race 0 strains (Pitblado and Kerr 1980). However, the increasing prevalence of race $1 P$. syringae pv. tomato strains able to overcome Pto/Prf-mediated NTI has led to the search for sources of resistance to these virulent strains. Since no race 1 resistance has 
been identified in cultivated tomato, wild relatives of tomato are likely to be the best potential source for this trait (Peralta et al. 2008).

Wild relatives of tomato have been screened previously to identify resistance against race $1 P$. syringae pv. tomato strains. One study reported a screen of introgression lines (ILs) derived from $S$. habrochaites LA1777, using the race 1 strain A9 from California (Thapa et al. 2015). The detection of four quantitative trait loci (QTLs), on chromosomes 1, 2, and 12 (two loci), explained the moderate resistance to this strain; however, overall they accounted for a small percentage of the variability observed (10.5 to $12.5 \%$ of the phenotypic variation) (Thapa et al. 2015). A second study identified two QTLs, on chromosomes 2 and 8, in S. habrochaites LA2109, that contributed to resistance to race 1 strain T1, which accounted for 24 and $26 \%$ of the phenotypic variability, respectively (Bao et al. 2015). Recently, another study reported a screen of 96 wild accessions and identified two accessions that display resistance toward race 1 strain T1, S. neorickii LA1329 and $S$. habrochaites LA1253. Resistance in LA1253 appears to be a complex genetic trait and its inheritance remains unclear (Hassan et al. 2017). Although together these QTLs might contribute to the breeding of enhanced race $1 P$. syringae pv. tomato resistance in tomato, their quantitative nature and relatively weak race 1 resistance limits their usefulness.

Here, we report the identification of race 1 resistance in a distantly related relative of tomato, Solanum lycopersicoides. The resistance is likely due to a single locus, which we refer to as Pseudomonas tomato race 1 (Ptrl). Ptrl confers resistance to several race $1 P$. syringae pv. tomato strains but not to the race 0 strain DC3000. A test of type III effectors that are present
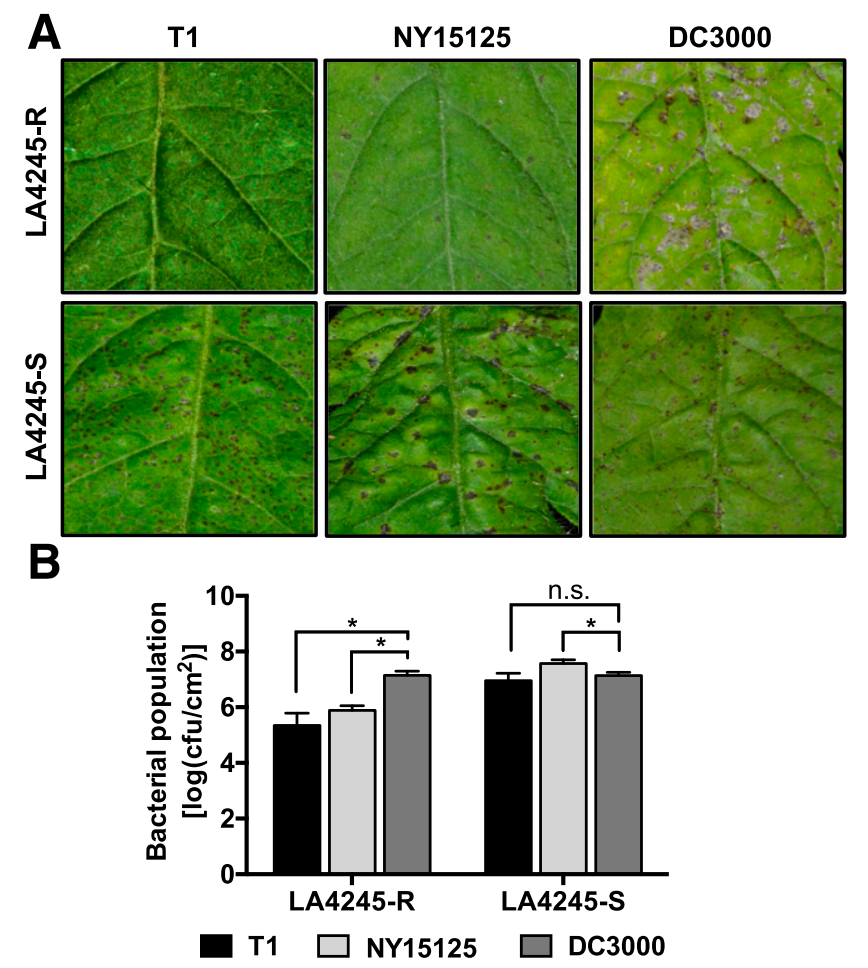

Fig. 1. LA4245-R confers resistance to certain strains of Pseudomonas syringae pv. tomato. A, Disease symptoms of LA4245-R and LA4245-S leaves vacuum-infiltrated with strains DC3000, NY15125, and T1 at $3 \times$ $10^{4} \mathrm{CFU} \mathrm{m} \mathrm{m}^{-1}$ and photographed 5 days later. B, Bacterial populations measured 2 days after inoculation with the $P$. syringae pv. tomato strains indicated. Significance was determined by a pair-wise $t$ test. An asterisk (*) indicates significant at $P<0.05$ and n.s. means not significant at $P>0.05$. Bars indicate the mean of three independent experiments using three plants per strain. Error bars represent \pm standard error of the mean. in race 1 strains but lacking in DC3000 identified AvrRpt2 as the effector recognized by Ptrl. AvrRpt2 is a cysteine protease that has been intensively studied because it cleaves RIN4, leading to activation of the Arabidopsis NLR protein RPS2 (Axtell et al. 2003; Mackey et al. 2003). By using site-directed mutagenesis of AvrRpt2, we discovered that, like RPS2, Ptr1 detects the proteolytic activities of this effector. Ptrl also detects the activity of AvrRpt 2 variants expressed by diverse bacterial phytopathogens, and this recognition correlates with ability of the variants to cleave the Arabidopsis RIN4 protein. Notably, Ptr1 conferred strong resistance to a Ralstonia pseudosolanacearum strain that expresses an AvrRpt2 homolog (RipBN); no resistance gene that gives protection against this important pathogen, causative agent of bacterial wilt disease, has been reported previously.

\section{RESULTS}

A locus on chromosome 4 from $S$. lycopersicoides LA2951 confers resistance to $P$. syringae pv. tomato race 1 strains.

During the summer of 2015 in upstate New York, a research plot of 110 S. lycopersicum VF36 × S. lycopersicoides LA2951 ILs (Canady et al. 2005) became naturally infected by $P$. syringae pv. tomato, resulting in severe symptoms of bacterial speck disease. However, two ILs, LA4245 and LA4277, remained essentially free of disease. LA4245 and LA4277 have large overlapping introgressed segments from chromosome 4 of S. lycopersicoides (Canady et al. 2005). The introgression in LA4245 is smaller, so we focused on that line for further characterization. In order to determine the race and other characteristics of the $P$. syringae pv. tomato strain involved in the outbreak, isolates were collected from the field and were analyzed. The presence of both avrPto and $a v r P t o B$ genes, immunoblot detection of the AvrPto protein, and subsequent inoculation of tomato plants with and without the Pto gene indicated the field isolates were race $0 P$. syringae pv. tomato strains (Kraus et al. 2017). One $P$. syringae pv. tomato strain, referred to as NY15125, was chosen for further analysis.

The chromosome 4 introgression segment in LA4245 is maintained in a heterozygous condition because homozygotes are very rarely obtained, as noted previously (Canady et al. 2005). We named the putative LA4245 resistance locus Ptrl and used a nomenclature in which its presence or absence is denoted as LA4245-R (Ptrl/ptr1) or LA4245-S (ptr1/ptr1), respectively. To follow up the field observations, LA4245 plants were inoculated with $P$. syringae pv. tomato strains DC3000, NY15125, and T1 in the greenhouse. Pathogen assays showed that DC3000 caused severe symptoms on LA4245-R plants, whereas NY15125 and T1 caused the appearance of few or no specks on LA4245-R, respectively (Fig. 1A). All the $P$. syringae pv. tomato strains caused more disease on LA4245$\mathrm{S}$ plants. Consistent with these observations, bacterial population assays showed that $\mathrm{T} 1$ attained levels approximately 65 -fold lower than DC3000 on LA4245-R plants (Fig. 1B). NY15125 grew to a level intermediate between T1 and DC3000 on LA4245-R. Such intermediate growth was observed previously for NY15125 on Pto-expressing plants (Kraus et al. 2017). The three $P$. syringae pv. tomato strains all attained similar population levels on LA4245-S plants (Fig. 1B). Therefore, the putative Ptrl locus from $S$. lycopersicoides LA2951 confers resistance to $P$. syringae pv. tomato strains NY15125 and, notably, T1, which is a race 1 strain.

$P$. syringae pv. tomato resistance in LA4245-R plants is due to recognition of the bacterial effector AvrRpt2.

A comparison of the type III effector genes in DC3000 and $\mathrm{T} 1$ identified eight that are present exclusively in T1 (avrA1, 
avrRpt2, hopAE1, hopAG1, hopAI1, hopAS1, hopS1, and hopW1) (Jones et al. 2015) (Supplementary Table S4). To determine whether LA4245-R resistance involves the recognition of any of these effectors, T1-specific effectors were individually cloned into the expression vector pCPP5372, the plasmids were introduced, via electroporation, into DC3000 $\triangle a v r P t o \Delta a v r P t o B$, and the strains were inoculated onto LA4245-R plants. All the strains except the one expressing AvrRpt 2 caused disease on LA4245-R plants. Subsequent experiments showed that the DC3000 strain expressing AvrRpt2 reached a population size 80-fold less in leaves of LA4245-R plants compared with LA4245-S plants; a DC3000 strain carrying an empty vector grew to the same level in the two plant lines (Fig. 2A).

Next, we asked whether $P$. syringae pv. tomato isolate NY15125, which was collected from the naturally infected tomato field, has the avrRpt 2 gene. Genome sequencing and PCR analysis confirmed the presence of avrRpt2 in this isolate (Supplementary Fig. S1). A comparison of AvrRpt2 protein sequences from NY15125 and T1 showed they are $100 \%$ identical. To investigate the activity of avrRpt 2 in NY15125, we generated a NY15125 AavrRpt2 deletion mutant and tested whether the strain was altered in its ability to grow on LA4245-R or LA4245-S plants. LA4245-R plants inoculated with the NY15125 wild-type strain supported an approximately 60-fold lower bacterial population compared with LA4245-S plants (Fig. 2B). In contrast, this difference was not observed when LA4245-R and LA4245-S plants were inoculated with NY15125 $\Delta a v r R p t 2$. Importantly, complementation of the mutant strain with avrRpt 2 restored the wild-type growth difference in LA4245-R plants (Fig. 2B).

AvrRpt 2 was originally identified in $P$. syringae pv. tomato JL1065 (Whalen et al. 1991). A comparison between the AvrRpt 2 protein sequences from JL1065 and NY15125 showed that the proteins have just two divergent amino acids; proline24 and alanine-152 in AvrRpt $2_{\mathrm{JL} 1065}$ are replaced by threonine and glycine, respectively in AvrRpt $2_{\mathrm{NY} 15125}$. We therefore investigated if there was any difference in effector recognition on LA4245-R plants when infected with JL1065 wild-type and JL1065 AavrRpt2 strains (Lim and Kunkel 2005). Bacterial population assays indicated that AvrRpt $2_{\mathrm{JL} 1065}$ is also recognized by LA4245-R (Supplementary Fig. S2). Finally, we tested three additional race $1 P$. syringae pv. tomato strains that all carry the avrRpt2 gene (NYT1, CA-A9, and CA-407) and found that LA4245-R is resistant to all of them, whereas LA4245-S was susceptible to these strains (Supplementary Fig. S3). Thus, Ptrl confers AvrRpt2-mediated resistance to multiple $P$. syringae pv. tomato race 1 strains.

\section{The Ptr1 locus and RPS2 detect the activity} of the same variants of AvrRpt2.

To gain insight into the mechanism of Ptrl recognition of AvrRpt2, we performed site-directed mutagenesis to alter amino acids in the effector that have been reported to be essential for its recognition by RPS2 in Arabidopsis (Chisholm et al. 2005; Jin et al. 2003; Lim and Kunkel 2004a and b). Ten AvrRpt2 variants were generated, of which eight have been reported to abolish recognition by RPS2 (Axtell et al. 2001, 2003; Jin et al. 2003; Lim and Kunkel 2004b); two variants, F70R, which disrupts the AvrRpt 2 autocleavage site, and E150S, were still recognized by RPS2 (Chisholm et al. 2005; Jin et al. 2003). Each AvrRpt2 variant was introduced into DC3000 on a plasmid and shown to be expressed by immunoblotting (Supplementary Fig. S4). The strains were then vacuum-infiltrated into LA4245-R and LA4245$\mathrm{S}$ plants, bacterial populations in leaves were measured, and plants were scored for disease symptoms. We observed that DC3000 expressing AvrRpt2 variants with the substitutions C122A, C122Y, G131D, G141D, G194R, or H208A grew to high levels and caused severe disease on LA4245-R plants, indicating a loss of Ptrl recognition (Fig. 3A and B). In contrast, similar to wild-type AvrRpt2, strains with variants F70R, E150S, Y191C, or D216E reached population levels, on average, approximately 60fold lower than the empty vector control strain and did not cause any disease symptoms on LA4245-R plants (Fig. 3A and B). All the DC3000 strains caused disease and reached similar population levels in LA4245-S plants (Supplementary Fig. S5).

Interestingly, AvrRpt2 variants with the substitutions Y191C and D216E were recognized by Ptrl but have been reported earlier not to be recognized by RPS 2 and to be unable to induce Arabidopsis RIN4 degradation (Lim and Kunkel 2004a). However, recently it was shown that Arabidopsis RIN4 is cleaved by variants AvrRpt2(Y191C) and AvrRpt2(D216E) (Eschen-Lippold et al. 2016). To investigate this discrepancy, Arabidopsis Col-0 RPS2 plants were inoculated with DC3000 expressing AvrRpt2 and several of the variants, including Y191C and D216E, and bacterial populations were measured 3 days later. We observed a significant reduction in bacterial growth and an absence of disease symptoms in Col-0 RPS2
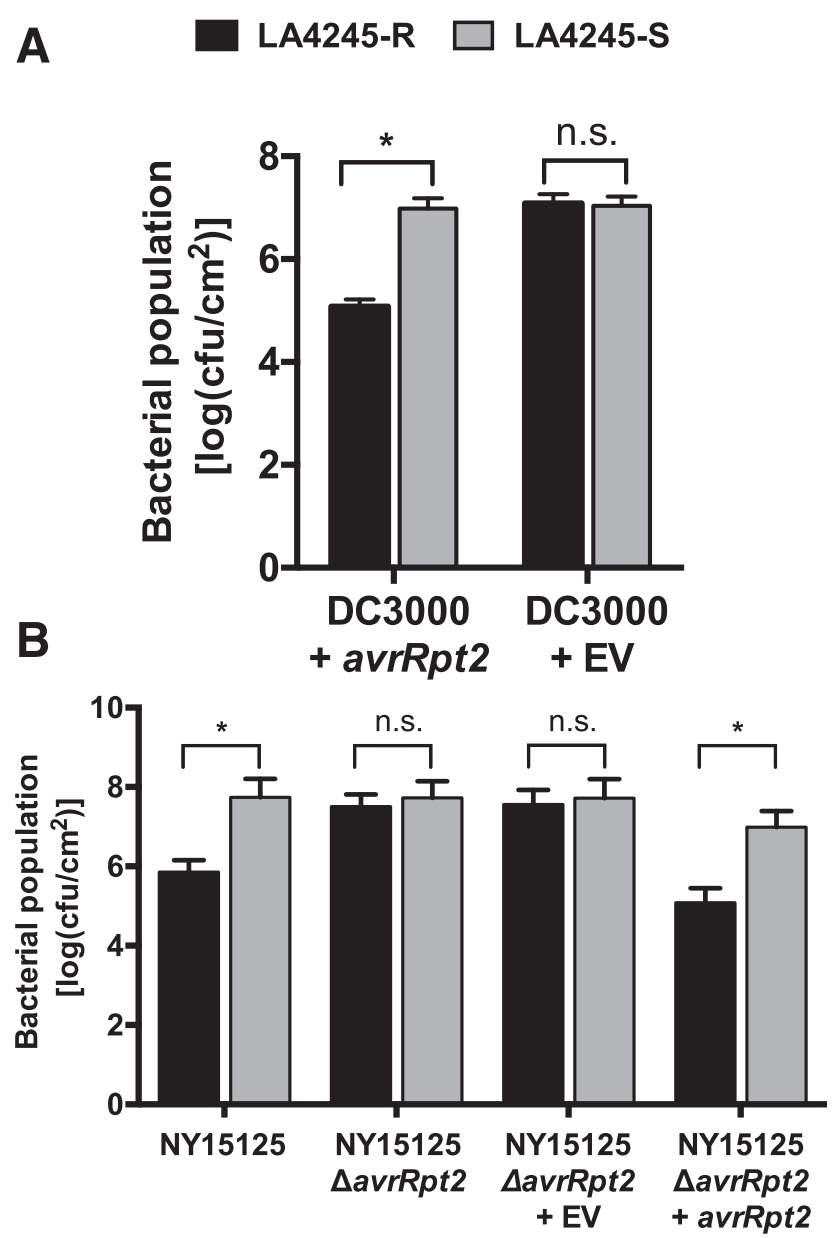

Fig. 2. Pseudomonas syringae pv. tomato race 1 resistance in LA4245-R plants is due to the recognition of the bacterial effector AvrRpt2. A, LA4245-R and LA4245-S plants were vacuum-infiltrated with DC3000 carrying avrRpt $2_{N Y 15125}$ or an empty vector $(\mathrm{EV})$ at $5 \times 10^{4} \mathrm{CFU} \mathrm{ml}^{-1}$ and bacterial populations were measured 2 days later. B, LA4245-R and

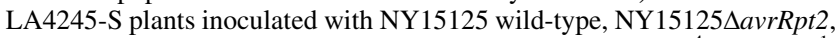

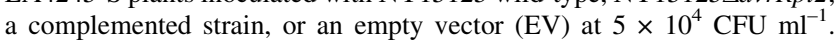
Bacterial populations were measured 2 days after inoculation. Significance was determined by a pair-wise $t$ test. An asterisk (*) indicates significant at $P<0.05$ and n.s. means not significant at $P>0.05$. Bars in both A and B indicate the mean of three independent experiments using three plants per strain. Error bars represent \pm standard error of the mean. 
plants inoculated with DC3000 carrying AvrRpt2 and the variants E150S, Y191C, and D216E; the F70R variant appeared to be weakly detected by RPS2 (Supplementary Fig. S6). Thus, Ptr1 and RPS 2 detect the activity of the same variants of AvrRpt 2 .

Ptr1 recognition of the AvrRpt2 variants correlates with the effector's ability to cleave tomato Rin4 proteins.

In Arabidopsis, AvrRpt2-mediated degradation of RIN4 leads to the activation of RPS2 (Mackey et al. 2003). Accordingly, we hypothesized that AvrRpt2 variants that are recognized by Ptrl will also be capable of degrading Rin4 in tomato. Tomato has three genes with similarity to AtRIN4 that are expressed in leaves and two of these are induced during Ptomediated NTI (SlRin4-1, SlRin4-2, and SlRin4-3 [Supplementary Table S5]). To avoid the Ptrl-mediated defense response, we vacuum-infiltrated LA4245-S plants with the DC3000 strains expressing each AvrRpt2 variant and wild-type AvrRpt2 and detected SIRin 4 abundance by immunoblotting $6 \mathrm{~h}$ later.
Wild-type AvrRpt2 and the variants F70R, E150S, Y191S, and $\mathrm{D} 216 \mathrm{~A}$ each induced a reduction in tomato Rin4 abundance that correlates with Ptrl recognition of these proteins in LA4245-R plants (Fig. 4A). DC3000 strains with AvrRpt2 variants C122A, G131D, G141D, G194R, H208A, or an empty vector, all of which caused disease on LA4245-R plants, failed to induce tomato Rin4 elimination (Fig. 4A). Similar experiments in Arabidopsis supported our earlier observations in that both AvrRpt2(Y191C) and AvrRpt2(D216E) were able to degrade RIN4 in rps2 plants (Fig. 4B). Therefore, there is a perfect correlation between the recognition of each AvrRpt2 variant by $P t r 1$ and the effector's ability to induce tomato Rin4 disappearance.

\section{AvrRpt2 proteins from different bacterial species} are recognized by $P$ trl.

Homologs of AvrRpt2 are found in diverse bacterial species including the plant pathogens Erwinia amylovora,
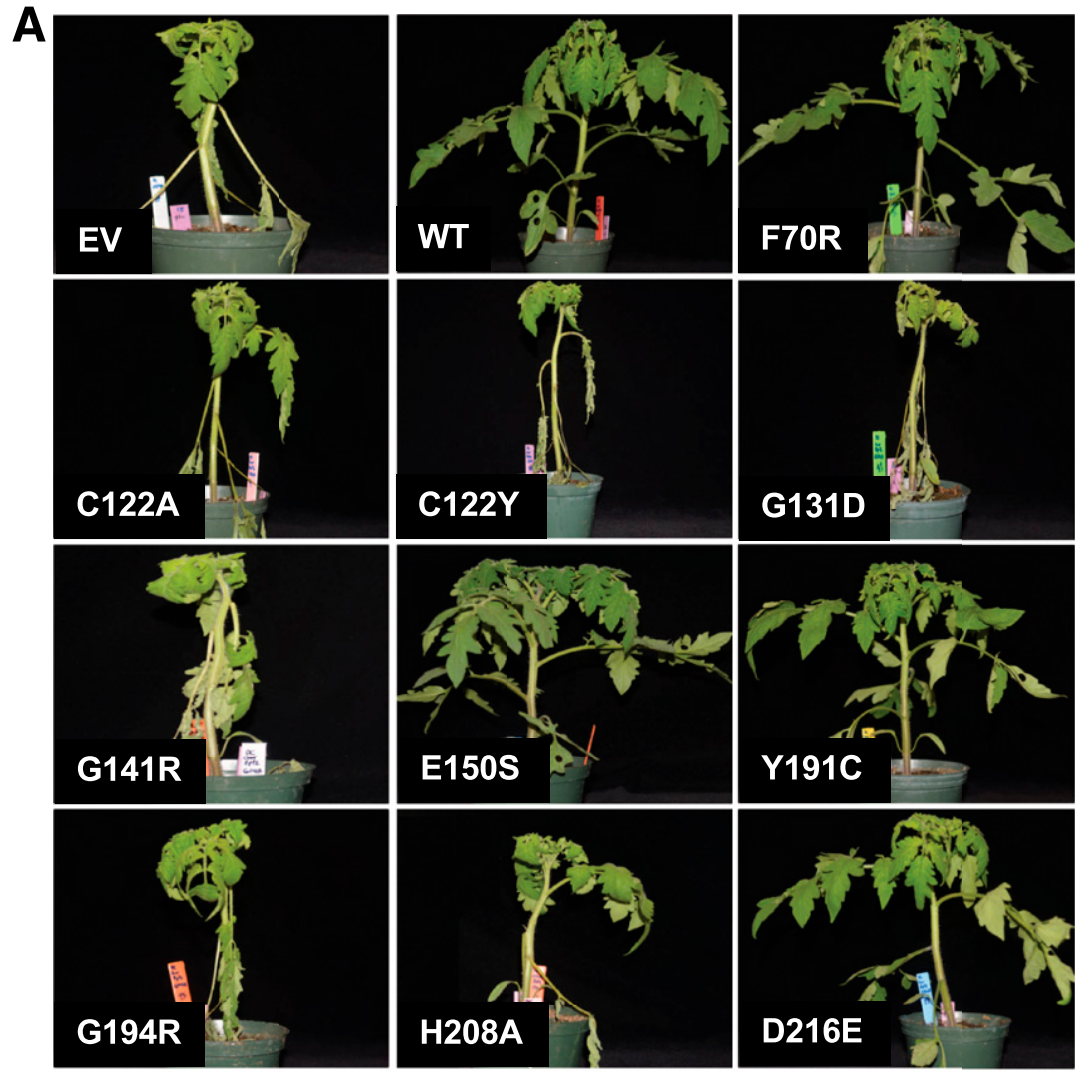

B

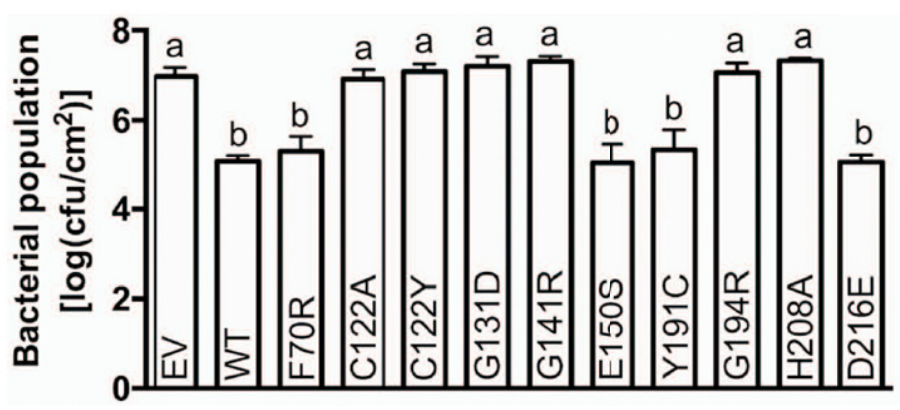

Fig. 3. Ptr1 and RPS2 detect the same variants of AvrRpt2. A, Symptoms of LA4245-R plants vacuum-infiltrated with Pseudomonas syringae pv. tomato DC3000 expressing avrRpt 2 wild type (WT), avrRpt 2 variants, or an empty vector (EV) at $5 \times 10^{4} \mathrm{CFU}^{-1}$. Photographs were taken 5 days after inoculation. B, Bacterial populations on LA4245-R plants inoculated with DC3000 expressing avrRpt 2 WT, avrRpt 2 variants, and empty vector (EV) were measured 2 days after inoculation. Significance was determined using analysis of variance with a Tukey's post hoc multiple comparison test; different letters indicate significant differences between treatments $(P<0.001)$. Bars indicate the mean of three independent experiments using three plants per strain. Error bars represent \pm standard error of the mean. 
R. pseudosolanacearum, Acidovorax citrulli, and Acidovorax avenae, the soil bacterium Burkholderia pyrrocinia, the fungal parasite Collimonas fungivorans, and the symbiotic bacteria Mezorhizobium huakuii and Sinorhizobium medicae (EschenLippold et al. 2016; Zhao et al. 2006). Some of these AvrRpt2 proteins have very divergent amino acid sequences or are truncated in comparison with $P$. syringae pv. tomato AvrRpt2 and we wished to determine whether Ptrl would recognize them. Agrobacterium-mediated expression (agroinfiltration) was used to express each AvrRpt 2 protein or a yellow fluorescent protein control in leaves of LA4245-R and LA4245-S. The AvrRpt 2 homologs from five of the eight bacterial species induced cell death in LA4245-R leaves but not in LA4245-S leaves, indicating their activity is recognized by Ptrl (Fig. 5). Detection of protein expression of each AvrRpt2 homolog was done via agroinfiltration in LA4245-S leaves (Supplementary Fig. S7).

\section{An amino acid substitution in AvrRpt2 that abolishes} its recognition by the apple Mr5 NLR resistance protein does not affect recognition by Ptr1.

Mr5 is an NLR fire blight resistance protein in apple that recognizes strains of E. amylovora that express AvrRpt2 (Fahrentrapp et al. 2012; Vogt et al. 2013). A single amino acid substitution in AvrRpt 2 at position 156 (cysteine to serine) abolishes recognition of the effector by $\mathrm{Mr} 5$. In AvrRpt $2_{\mathrm{NY} 15125}$, the comparable residue is tyrosine 191. Since a Y191C substitution in AvrRpt2 was shown previously to be recognized by Ptrl (Fig. 3), we asked whether a Y191S substitution in AvrRpt2 would abolish Ptrl recognition as it does for Mr5 recognition. Inoculation of LA4245-R plants with a DC3000 strain expressing AvrRpt2(Y191S) revealed this variant is recognized by Ptrl, as it induced disease resistance and reduced bacterial growth compared with an empty vector DC3000 control strain (Fig. 6A and B). Mr5 and Ptr1, therefore, appear to use different mechanisms to detect AvrRpt2 activity.

\section{Ptr1 confers resistance to bacterial wilt disease caused by $R$. pseudosolanacearum.}

Agroinfiltration experiments indicated that RipBN, the AvrRpt2 homolog from $R$. pseudosolanacearum, is recognized by Ptrl (Fig. 5). The ripBN gene is present in a strain of $R$. pseudosolanacearum, CMR15, that was collected from tomato in Cameroon in 2009 (Mahbou Somo Toukam et al. 2009) and was later sequenced (Remenant et al. 2010). Bacterial wilt, caused by $R$. pseudosolanacearum, is a devastating disease for which no NLR-mediated resistance in tomato has been reported (Huet 2014). We therefore soil drench-inoculated LA4245-R and LA4245-S plants with CMR15 and scored the number of plants showing symptoms of bacterial wilt over a 13-day time period. Beginning at 6 days after inoculation, LA4245-S plants started to wilt and, 13 days after inoculation, approximately $70 \%$ of the plants were dead (Fig. 7A and B). Remarkably, at this timepoint, there was $100 \%$ survival of the LA4245-R plants. Ptrl-mediated resistance can therefore be effective against bacterial wilt and might be useful for controlling bacterial wilt disease in tomato-growing areas that have $R$. pseudosolanacearum strains expressing RipBN.

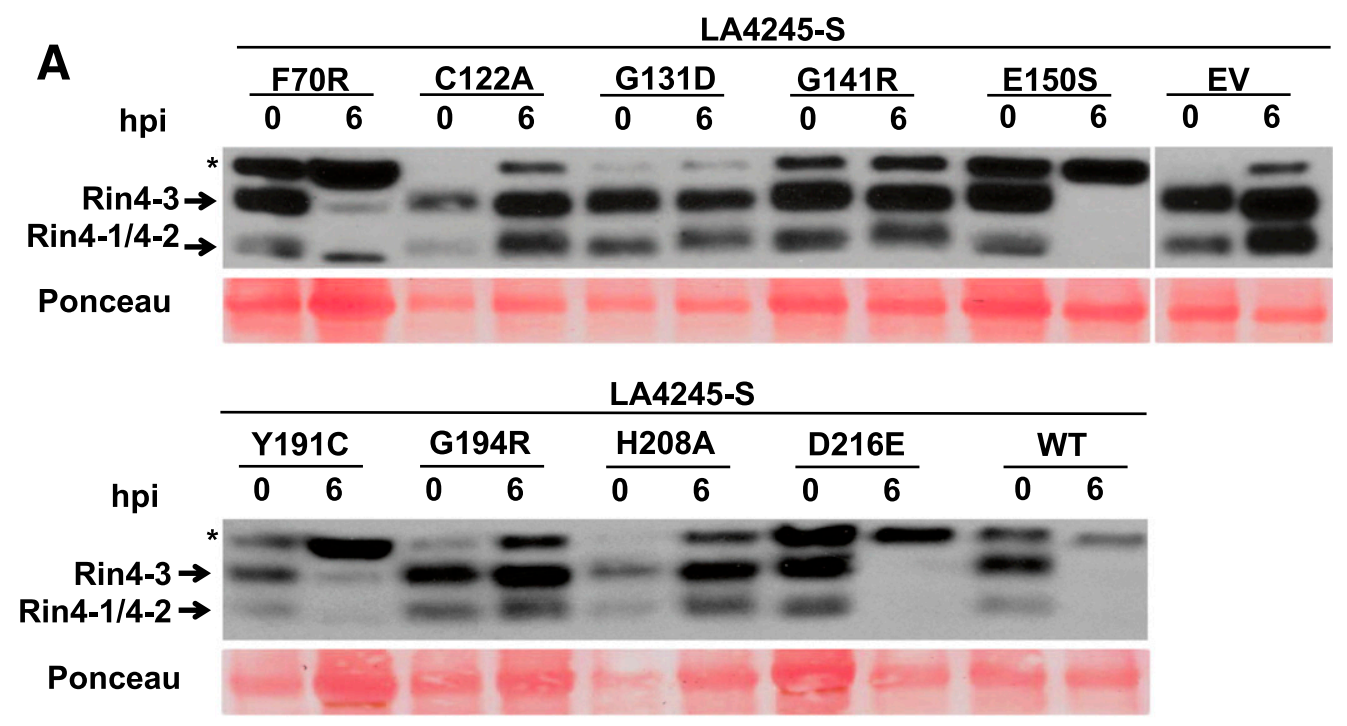

B

A. thaliana rps2

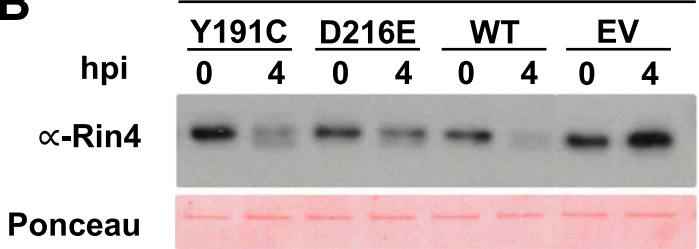

Fig. 4. AvrRpt2 variants F70R, E150S, Y191C, D216E, and AvrRpt2 wild-type, which are recognized by Ptrl, are able to degrade tomato Rin4 proteins. A, Degradation of the endogenous tomato Rin4 proteins after vacuum infiltration of LA4245-S leaves with Pseudomonas syringae pv. tomato DC3000 strains carrying avrRpt2 wild type (WT), avrRpt2 variants, or an empty vector (EV). Plant tissue was harvested 0 and $6 \mathrm{~h}$ postinfiltration (hpi). Total protein extracted from infiltrated plants was subjected to immunoblotting using a $\propto$-RIN4 antibody. Locations of tomato Rin4-1, Rin4-2, and Rin4-3 are shown. Asterisks indicate an unknown cross-reacting protein. B, Arabidopsis Col-0 rps 2 leaves were syringe-infiltrated with DC3000 carrying avrRpt2 wild type (WT), avrRpt2 variants, or an EV. Leaf tissue was harvested $4 \mathrm{hpi}$. Total protein extracted from infiltrated leaves was subjected to immunoblotting using a $\propto$-RIN4 antibody. Ponceau staining shows the amount of protein loaded in each lane. 
No RPS2, Mr5, or RIN4 orthologs are present in the $S$. lycopersicoides chromosome 4 introgression segments of LA4245-R.

To initiate the map-based cloning of Ptrl, we generated sequence data, at $14 \times$ coverage of the Heinz 1706 reference genome from genomic DNA of LA4245-R, using an Illumina HiSeq2000. The reads were mapped to the S. lycopersicum Heinz 1706 genome sequence to identify areas of high sequence polymorphism. This analysis revealed that LA4245-R contains two $S$. lycopersicoides introgression segments on chromosome 4 in the background of the tomato parent VF36. One small segment lies within coordinates 1 to 260,000 bp $(260 \mathrm{~kb})$ and the other lies between coordinates 4,480,000 and $62,030,000 \mathrm{bp}$ (approximately $57.5 \mathrm{Mb}$ ) (Supplementary Fig. S8A). A high-quality genome sequence of $S$. lycopersicoides LA2951, a parent of the ILs, has been generated recently (discussed below). Synteny between Heinz 1706 and LA2951 was determined, and gene models predicted to be in the introgressed regions of LA4245-R were identified in the S. lycopersicoides annotation. Ptrl recognition of AvrRpt2 suggests it likely encodes an NLR protein or possibly a guardee such as Rin4. No NLR-encoding genes are annotated within the small introgression segment and just 14 NLR genes are annotated within the large $S$. lycopersicoides introgression segment. Interestingly, none of these 14 genes encode a predicted protein with similarity to RPS2 or Mr5. In fact, the $S$. lycopersicoides genes with predicted proteins having the highest similarity to RPS2 and Mr5 are all located on other chromosomes (Supplementary Table S6). None of the four Rin4 genes in tomato are located on chromosome 4.

\section{DISCUSSION}

From a serendipitous observation during a natural occurrence of bacterial speck disease, we identified and further characterized two $S$. lycopersicoides ILs that have strong resistance to multiple race 1 strains of $P$. syringae pv. tomato. Such resistance is important, since race $1 P$. syringae pv. tomato strains are becoming increasingly common throughout the world and yet no simply inherited genetic resistance to these strains is known. The two ILs contain a large overlapping introgression segment from $S$. lycopersicoides chromosome 4, which carries a putative locus that we refer to as $P t r 1$, which recognizes the effector AvrRpt2. This effector is present in $P$. syringae pv. tomato strains collected from diverse tomato-growing regions including all race $1 P$. syringae pv. tomato strains for which a
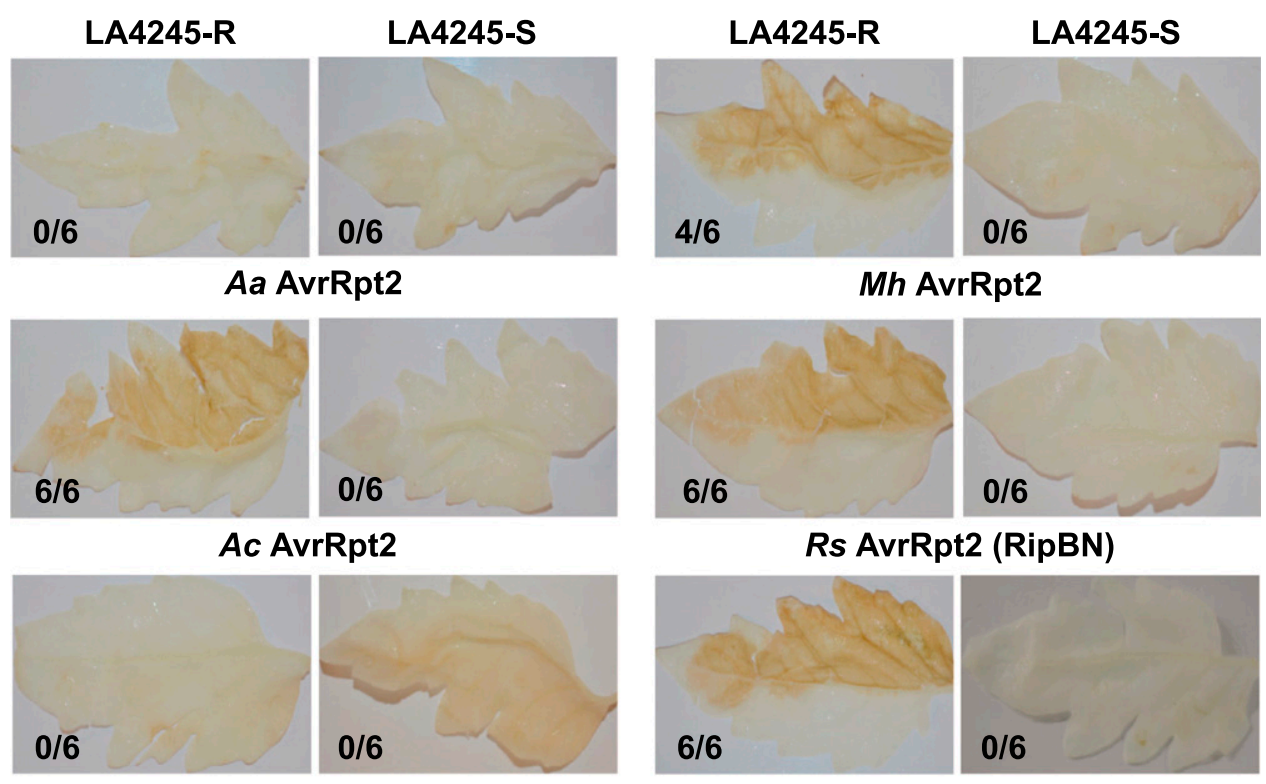

Bp AvrRpt2

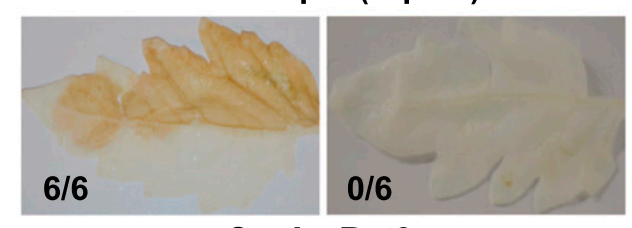

Sm AvrRpt2
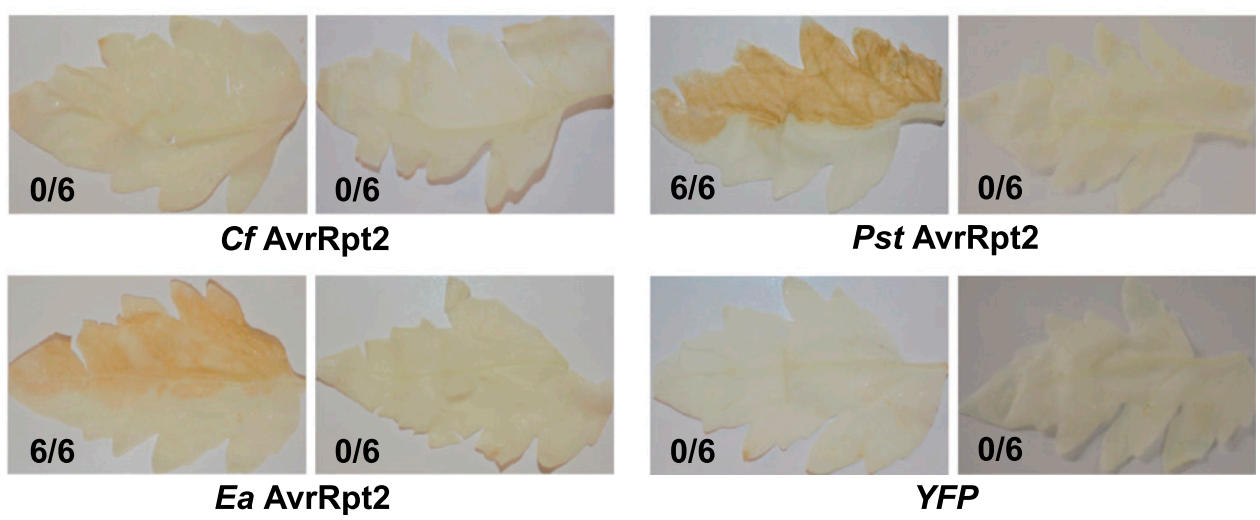

Fig. 5. AvrRpt2 homologs from diverse bacteria are recognized by Ptr1. Agroinfiltration of each avrRpt2 homolog (Aa, Acidovorax avenae; Ac, Acidovorax citrulli; Bp, Burkholderia pyrrocinia; Cf, Collimonas fungivorans; Ea, Erwinia amylovora; Mh, Mezorhizobium huakuii; Rs, Ralstonia pseudosolanacearum; Sm, Sinorhizobium medicae; Pst, Pseudomonas syringae pv. tomato) and a control (yellow fluorescent protein [YFP]) into LA4245-R and LA4245-S leaves. Detached leaves were cleared with ethanol to better visualize cell death associated with AvrRpt 2 recognition. Photographs were taken 4 days after infiltration. Shown are the number of times cell death was observed over the total number of agroinfiltrations performed. 
genome sequence is available (T1, K40, NY-T1, CA-A9, CA407 ) and some race 0 P. syringae pv. tomato strains (JL1065, NY15125). The Ptrl locus, if combined with Pto in the same tomato variety, has the potential to become an important component of bacterial speck disease control. Here, we compare the activity of Ptrl to Arabidopsis RPS2 and apple Mr5, two genes that also detect AvrRpt2, discuss the potential utility of Ptrl and approaches to identifying the Ptrl gene, and we propose the definition of additional $P$. syringae pv. tomato races to account for the fact that two NTI loci are now known to confer resistance to bacterial speck disease.

Cleavage of Rin4 by AvrRpt2 in Arabidopsis leads to activation of RPS2 and resistance to $P$. syringae pv. tomato, although the specific mechanism by which Rin4 degradation activates RPS2 is unknown (Day et al. 2005; Toruño et al. 2019). Our analysis of AvrRpt 2 variants revealed a perfect correlation between the ability of a variant to degrade tomato

A

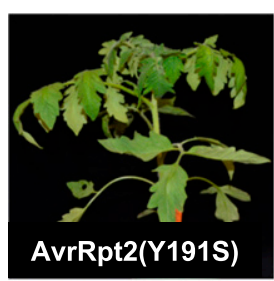

LA4245-R

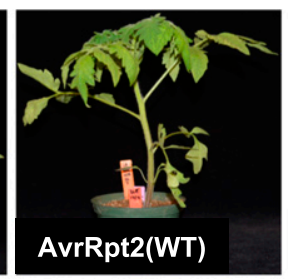

LA4245-S
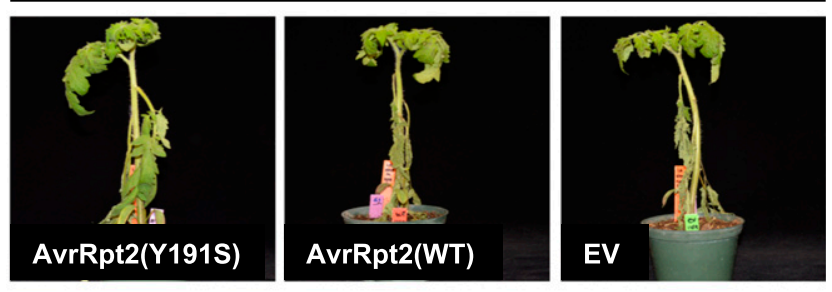

B

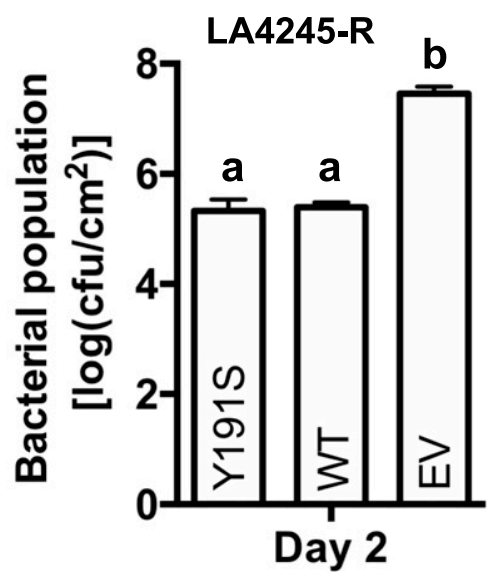

Fig. 6. Pseudomonas syringae pv. tomato AvrRpt2(Y191S) variant, analog of the Erwinia amylovora AvrRpt2(C156S) virulent variant is recognized by Ptr1. A, Disease symptoms of LA4245-R and LA4245-S plants 4 days after inoculation with DC3000 expressing avrRpt2(Y191S), avrRpt2 wild type (WT), or an empty vector $(\mathrm{EV})$ at $5 \times 10^{4} \mathrm{CFU} \mathrm{ml}{ }^{-1}$. B, Bacterial populations were measured in LA4245-R plants 2 days after inoculation. Significance was determined using analysis of variance with a Tukey's post hoc multiple comparison test, and different letters indicate significant differences between treatments $(P<0.001)$. Bars indicate the mean of three plants and error bars represent \pm standard deviation. Results shown are representative of three independent experiments.
Rin4 proteins and its recognition by Ptrl and RPS2; AvrRpt2 variants that do not degrade Rin4 are not recognized by Ptrl or $R P S 2$. It is possible, therefore, that the Ptr1 and RPS2 proteins are activated via the same mechanism subsequent to Rin4 degradation, although the possibility that a mechanism specific to tomato or Arabidopsis exists cannot currently be ruled out. The apple Mr5 protein detects activity of AvrRpt2 from E. amylovora. The AvrRpt2 $2_{\mathrm{Ea}}$ effector does not induce Arabidopsis Rin4 degradation when the proteins are transiently cooverexpressed in $N$. benthamiana, although it is possible that this method masks moderate degradation; whether Rin4 degradation in apple is correlated with $\mathrm{Mr} 5$ activation has not been reported (Vogt et al. 2013). Interestingly, an AvrRpt $2_{\text {Ea }}$ variant that is not detected by Mr5 is detected by Ptrl and is able to degrade Arabidopsis RIN4, suggesting that the recognition mechanism of these two proteins is different.

Using an anti-AtRin4 antibody, we observed that all three tomato Rin4-like proteins that are expressed in leaves were degraded in the presence of AvrRpt2. Soybean also has four Rin4 proteins, and virus-induced gene silencing experiments showed that just two of them, GmRIN4a and GmRIN4b, play a role in the hypersensitive response induced by AvrB and the NLR protein Rpg1b (Selote and Kachroo 2010). A subsequent study showed that overexpression of any one of the four soybean RIN4s with Rpg1b/AvrB in leaves of Nicotiana glutinosa caused a hypersensitive response; the authors concluded that the expression level differences in these two studies might account for these different observations (Kessens et al. 2014).
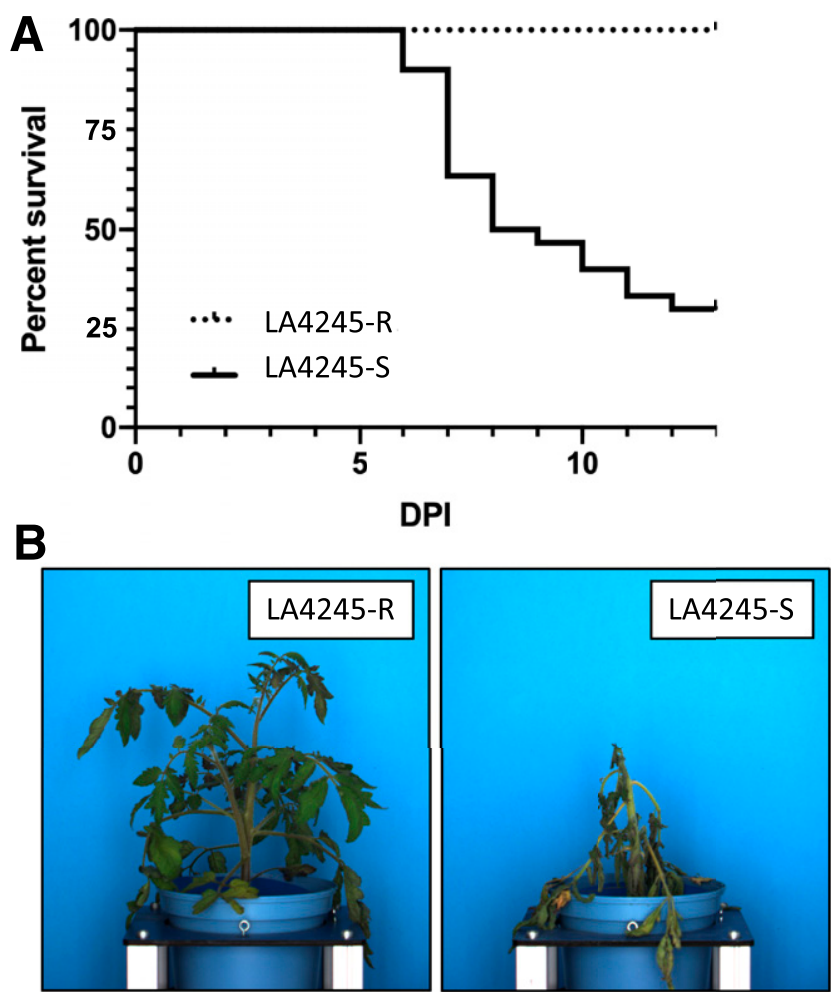

Fig. 7. Ptrl confers resistance to Ralstonia pseudosolanacearum CMR15 expressing AvrRpt 2 homolog RipBN. A, LA4245-R plants $(n=25)$ and LA4245-S plants $(n=30)$ were soil drench-inoculated with $50 \mathrm{ml}$ of $10^{8} \mathrm{CFU} \mathrm{ml^{-1 }}$ Ralstonia pseudosolanaceraum CMR15. The percentage of plants surviving (showing no wilt symptoms) or dying (showing severe wilting) 1 to 13 days postinoculation (DPI) is shown. The two survival curves are significantly different at $P<0.0001$, using the Mantel-Cox test. B, Photographs taken 13 days after inoculation show extreme wilting of a LA4245-S plant (right) and no wilting of a LA4245-R plant (left). Results shown are representative of three independent experiments. 
Apple contains two Rin4-like genes although, as noted above, any specific roles they might have in activation of Mr5 have not yet been reported (Fahrentrapp et al. 2012; Vogt et al. 2013). In the future, we will investigate the requirement of the three tomato Rin4 proteins for activation of Ptr1, using both CRISPR-generated mutations in the corresponding genes and, once the Ptrl gene is identified, transient coexpression in N. benthamiana.

We found that Ptrl is able to recognize AvrRpt2 homologs from a diverse array of different bacteria, including several plant pathogens. Each of the AvrRpt 2 proteins recognized by Ptr 1 had been previously shown to also induce AtRin4 degradation in Arabidopsis, although their ability to activate RPS2-mediated resistance was not reported (Eschen-Lippold et al. 2016). If avrRpt 2 homologs are widespread in field isolates of Acidovorax citrulli and E. amylovora, then our results suggest that Ptrl might be useful if expressed transgenically in cucurbits to control bacterial fruit blotch caused by Acidovorax citrulli and in apple or pear to confer resistance to fire blight caused by E. amylovora. Despite extensive screening of tomato germplasm, no single $R$ gene has been identified that confers resistance to bacterial wilt disease caused by $R$. pseudosolanacearum (Huet 2014). We found that Ptrl was remarkably effective in preventing symptoms of bacterial wilt, in a growth chamber assay, using strain CMR15. Unfortunately, CMR15 seems to be a rare example of a $R$. pseudosolanacearum strain that expresses an AvrRpt2 homolog (RipBN) (Peeters et al. 2013) (LIPM Ralso T3E database) and Ptrl will, therefore, likely not be of broad utility for controlling bacterial wilt disease. Nevertheless, further study of interaction between CMR15 and LA4245-R might provide some useful insights into the molecular basis of the NTI response against $R$. pseudosolanacearum that is induced by Ptrl.

Considering that Ptrl plays a role in detecting the type III effector AvrRpt2, it seems most likely that it encodes an NLR, although it could encode a decoy or guardee protein that is monitored by an NLR. In either case, one of these genes must be located in the introgression segments, although the other one may or may not lie in the introgressions. Examples of each possibility are known; the Pto (decoy) and Prf (NLR) genes are located in a 20-kb region of chromosome 5, whereas the RIN4 (guardee) and RPS2 (NLR) genes are located on a different chromosome in Arabidopsis. In the Heinz 1706 tomato reference genome sequence, chromosome 4 has 56 NLR-encoding genes, the most of any chromosome; 43 of these genes are clustered tightly within a $100-\mathrm{kb}$ region, with the other 13 located throughout the rest of the chromosome. S. lycopersicoides has 66 NLR-encoding genes on chromosome 4 with a similar distribution as seen in Heinz 1706-58 are tightly clustered at one end and eight are distributed along the chromosome. One boundary of the large introgression segment occurs in the middle of the large NLR cluster, which potentially eliminates as Ptrl candidates 51 NLR-encoding genes. Each of the remaining 14 NLR genes is a candidate for Ptrl. None of these candidates encode proteins with obvious similarity to RPS2 or Mr5, and, if one of these is Ptr1, it will be just the third known example of convergent evolution in different plant species for recognition of the same effector (Ashfield et al. 2004; Carter et al. 2019). The obvious decoy/guardee proteins that might be involved with AvrRpt2 recognition in tomato are the three Rin4-like proteins expressed in leaves. None of these genes are located on chromosome 4 of tomato or S. lycopersicoides. Another, perhaps less likely, scenario that should be considered is that a gene in the introgression segment encodes a novel host protein that acts with Rin4 to activate an NLR located on another chromosome in VF36. All these possibilities will be investigated in the future as we seek to identify the genes involved in AvrRpt2 recognition and understand the associated molecular mechanisms.

Although LA4245-R plants are morphologically very similar to VF36, the IL line has two introgression segments on chromosome 4, including one large (about $57.5 \mathrm{Mb}$ ) segment encompassing the majority of the 66.56-Mb chromosome; however, this IL line cannot be maintained in a homozygous condition. If Ptrl is to be useful for control of speck disease, it will need to be introgressed into other tomato breeding lines and it will be necessary to reduce the size of the introgressed segment in order to reduce 'linkage drag' (i.e., deleterious alleles). However, recombination is often severely suppressed in plants carrying chromosomal regions from a wild relative of tomato, and $S$. lycopersicoides is particularly distant from cultivated tomato (Grandillo et al. 2011). One approach that might be used in this case is to cross LA4245-R with a species that is phylogenetically intermediate between tomato and $S$. lycopersicoides. A good candidate for such a 'bridge' species is $S$. pennellii which has been shown previously to be useful in increasing recombination frequency in $S$. lycopersicoides introgression regions (Canady et al. 2006). Importantly, Ptrl and Pto are located on different chromosomes (4 and 5, respectively), which will facilitate introgressing them both into advanced breeding lines.

The identification of a second $R$ gene that confers resistance to bacterial speck disease presents the opportunity to extend the currently defined race structure of $P$. syringae pv. tomato. The two current races were defined based on the Pto gene in which race 0 strains express either or both of the type III effectors AvrPto and AvrPtoB, and race 1 strains evade Pto detection by either losing or mutating these effector genes or, in the case of AvrPtoB, suppressing its protein accumulation (Kunkeaw et al. 2010; Lin et al. 2006; Pedley and Martin 2003). Based on the discovery of Ptrl and focusing on $P$. syringae pv. tomato strains related to $\mathrm{T} 1$, we propose that race 0 strains might be considered the original state of the pathogen and refer to those strains that express avrPto or avrPtoB along with avrRpt2 (Table 1). Race 1 can then refer to strains that express avrRpt2 but lack avrPto or avrPtoB. A newly defined race 2 would refer to strains that have $a v r P t o$ or avrPtoB but lack avrRpt2. Finally, a hypothetical strain that

Table 1. Proposed races for Pseudomonas syringae pv. tomato based on the Pto and Ptrl genes ${ }^{\mathrm{a}}$

\begin{tabular}{|c|c|c|c|c|c|c|}
\hline \multirow[b]{2}{*}{ Race } & \multirow[b]{2}{*}{ Example } & \multirow[b]{2}{*}{ References } & \multirow[b]{2}{*}{ Relevant effectors } & \multicolumn{3}{|c|}{$R$ gene present } \\
\hline & & & & Pto & Ptr1 & None \\
\hline 0 & JL1065 NY15125 & Whalen et al. 1991; Kraus et al. 2017 & $\begin{array}{l}\text { Either AvrPto, AvrPtoB or } \\
\text { both, AvrRpt } 2\end{array}$ & $\mathrm{R}$ & $\mathrm{R}$ & $S$ \\
\hline 1 & T1, NYT1, CA-A9, CA-407 ${ }^{\mathrm{b}}$ & $\begin{array}{l}\text { Almeida et al. 2009; Jones et al. 2015; } \\
\text { Kunkeaw et al. } 2010\end{array}$ & AvrRpt2 & S & $\mathrm{R}$ & $S$ \\
\hline 2 & $\operatorname{Max} 13$ & Yan et al. 2008 & Either AvrPto, AvrPtoB or both & $\mathrm{R}$ & S & $\mathrm{S}$ \\
\hline 3 & Unknown & & No AvrPto, AvrPtoB, AvrRpt2 & $\mathrm{S}$ & $\mathrm{S}$ & $\mathrm{S}$ \\
\hline
\end{tabular}

${ }^{a}$ Resistance and susceptibility are denoted as $\mathrm{R}$ and $\mathrm{S}$, respectively.

b Race 1 strains T1, NYT1, CA-A9, and CA-407 are positive for the presence of the avrPtoB gene, but AvrPtoB protein does not accumulate for unknown reasons. 
lacks all three of these effectors would be defined as race 3 . Examples of race 0 , race 1 , and race $2 P$. syringae pv. tomato strains along with the ability of one or both Ptrl and Pto to recognize them are provided in Table 1.

In summary, Ptrl has the potential to become an important component (along with Pto) for the control of bacterial speck disease in tomato. In addition, the eventual cloning and characterization of the gene will allow its molecular characterization and, in particular, might shed light on whether it uses the same or a different mechanism than used by RPS2 and Mr5 to respond to AvrRpt2-mediated degradation of Rin4.

\section{MATERIALS AND METHODS}

\section{Bacterial strains and plasmids.}

Pseudomonas syringae pv. tomato strains DC3000 (Buell et al. 2003), NY15125 (Kraus et al. 2017), T1 (Almeida et al. 2009), JL1065 (Whalen et al. 1991), NYT1 (Jones et al. 2015), CA-A9, and CA-407 (Kunkeaw et al. 2010) were grown on King's B (KB) (King et al. 1954) semiselective media at $30^{\circ} \mathrm{C}$ (Supplementary Table S1). Ralstonia pseudosolanacearum CMR15 (Remenant et al. 2010) was grown on rich B medium (27.7 mM glucose, $10 \mathrm{~g}$ of bacto-peptone per liter, $1 \mathrm{~g}$ of yeast extract per liter, $1 \mathrm{~g}$ of casamino acids per liter). pCPP5372 plasmids (Oh et al. 2007) carrying wild-type $a v r R p t 2_{\mathrm{NY} 15125}$, avrRpt 2 variants, or the empty vector were introduced into DC3000 by electroporation (Supplementary Tables S2 and S3). All $P$. syringae pv. tomato strains were stored in $20 \%$ glycerol + $60 \mathrm{mM}$ sucrose at $-80^{\circ} \mathrm{C}$. Escherichia coli TOP10 was used for plasmid maintenance and were grown in Luria-Bertani (LB) medium at $37^{\circ} \mathrm{C}$

\section{Plant material.}

Solanum lycopersicoides IL seeds of LA4245 and LA4277 were obtained from the Tomato Genetics Resource Center. The genotype of LA4245 can be heterozygous for the presence of Ptrl (Ptr1/ptrl) (LA4245-R) or homozygous for the lack of the gene (ptrl/ptrl) (LA4245-S). S. lycopersicoides ILs were grown in a greenhouse at $24^{\circ} \mathrm{C}$ during daylight and $22^{\circ} \mathrm{C}$ at night. Nicotiana benthamiana $\mathrm{Nb}-1$ (Bombarely et al. 2012) was maintained in a growth chamber with $16 \mathrm{~h}$ of light at $24^{\circ} \mathrm{C}$ and $8 \mathrm{~h}$ of dark at $20^{\circ} \mathrm{C}$ and $50 \%$ humidity. Tomatoes and $N$. benthamiana plants were grown in Cornell Osmocote Mix soil $\left(0.16 \mathrm{~m}^{3}\right.$ peat moss, $0.34 \mathrm{~m}^{3}$ vermiculite, $2.27 \mathrm{~kg}$ of lime, $2.27 \mathrm{~kg}$ of Osmocote Plus15-9-12, and $0.54 \mathrm{~kg}$ of Uni-Mix 115-11 [Everris, Israeli Chemicals Ltd.]). After pathogen inoculation, plants were moved to a growth chamber with $25^{\circ} \mathrm{C}$, $50 \%$ humidity, and $16 \mathrm{~h}$ of light. Arabidopsis thaliana accession Columbia (Col-0) seeds were ethanol-sterilized, were suspended in $1 \mathrm{ml}$ of water, and were cold stratified for 2 days at $4^{\circ} \mathrm{C}$. A. thaliana was grown in Fafard Mix (Sungro Horticulture) in a growth chamber under fluorescent lighting $\left(100 \mu \mathrm{mol} \mathrm{m} \mathrm{m}^{-2} \mathrm{~s}^{-1}\right)$ with a 12 -h light and 12 -h dark cycle at $21^{\circ} \mathrm{C}$ and $40 \%$ humidity.

\section{Genome sequencing, assembly, and type III effector annotation of NY15125.}

The NY15125 genome was sequenced to $163 \times$ coverage with long reads from the PacBio RSII platform. A Canu assembly was performed with a stringent error rate (corrected error rate $=$ 0.035) (Koren et al. 2017). Illumina sequencing was also done to generate paired-end reads for a coverage of $114 \times$. Adapter clipping and quality filtering of the Illumina reads was done with Trimmomatic (Bolger et al. 2014). Concordant readmapping of the Illumina paired-end reads was used to evaluate the quality of the assembly. Two rounds of base-level error corrections were done with PacBio reads using Arrow (available online), followed by two rounds of error correction with Illumina reads using Pilon (Walker et al. 2014). The polished assembly includes a $6.2 \mathrm{Mb}$ chromosome and three putative plasmids $(88,116$, and $122 \mathrm{~kb})$. It was annotated with Prokka (Seemann 2014), using proteins from the T1 genome (Almeida et al. 2009) as supporting evidence. The NY15125 chromosome was compared with the DC3000 and T1 genomes using BRIGG (Alikhan et al. 2011). Pseudomolecules were constructed from the deposited contigs for $P$. syringae pv. tomato NY15125 and were annotated using MG-RAST (Meyer et al. 2008). Effector genes were identified from the MG-RAST annotation, by alignment with other $P$. syringae pv. tomato sequences, and based on proximity to HrpL binding sites, predicted using the methods described previously (Saha and Lindeberg 2013). The NY15125 genome sequence and plasmid sequences are available from GenBank (accession numbers CP034558 to CP034561).

\section{Development of a $P$. syringae pv. tomato

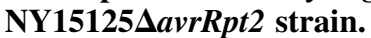

A 1,024-bp promoter fragment and an 841-bp fragment downstream of the avrRpt 2 gene sequence were PCR-amplified and EcoRI or $X m a I$ restriction sites were added, respectively. Fusion of both DNA fragments was cloned into the suicide vector pK18mobsacB and was transformed into Escherichia coli S17-1. Deletion of avrRpt2 in NY15125 was performed by biparental mating, as described previously (Kraus et al. 2017) with modifications (Kvitko and Collmer 2011).

\section{$P$. syringae pv. tomato inoculation and population assays in tomato.}

P. syringae pv. tomato strains were grown on $\mathrm{KB}$ plates for 2 days at $30^{\circ} \mathrm{C}$. Strains were diluted in $10 \mathrm{mM} \mathrm{MgCl}_{2}+0.002 \%$ Silwet L-77 at a final concentration of $5 \times 10^{4} \mathrm{CFU} \mathrm{ml}{ }^{-1}$. Fourweek-old plants were vacuum-infiltrated, and three leaf disk samples ( $7 \mathrm{~mm}$ in diameter) were collected at $2 \mathrm{~h}$ (day 0$)$ and 2 days postinoculation (dpi) to quantify bacterial populations. The experiments were repeated three times. Results shown are the mean of three independent experiments using three biological replicates per strain, including standard error of the mean. Photographs for each technical replicate were taken 7 dpi. Statistical analyses were performed using Prism 6.0 (GraphPad software).

\section{$P$ syringae pv. tomato inoculation and population assays in A. thaliana.}

Five-week-old plants were dip-inoculated for $20 \mathrm{~s}$ in a bacterial suspension $\left(1 \times 10^{8} \mathrm{CFU} \mathrm{ml}^{-1}\right.$ of $P$. syringae pv. tomato $)$ containing $10 \mathrm{mM} \mathrm{MgCl} 2+0.02 \%$ Silwet L-77. Bacterial populations were measured 3 dpi by submerging the aerial plant tissue in $10 \mathrm{mM} \mathrm{MgCl}_{2}+0.2 \%$ Silwet L- 77 for $2 \mathrm{~h}$ at $28^{\circ} \mathrm{C}$. The bathing solution was serially diluted and plated (Tornero and Dangl 2002). Experiments were repeated three times. Results shown are the mean of three independent experiments using three biological replicates per strain, including standard error of the mean. Statistical analyses were performed using Prism 6.0 (GraphPad software).

\section{Immunodetection of AvrRpt2 proteins in $P$. syringae pv. tomato.}

Strains of $P$. syringae pv. tomato grown on $\mathrm{KB}$ plates for 2 days at $30^{\circ} \mathrm{C}$ were resuspended in $\mathrm{hrp}$-inducing liquid minimal media [50 mM KH $\mathrm{PO}_{4}, 7.6 \mathrm{mM}\left(\mathrm{NH}_{4}\right)_{2} \mathrm{SO}_{4}, 1.7 \mathrm{mM}$ $\mathrm{NaCl}, 1.7 \mathrm{mM} \mathrm{MgCl} 2,10 \mathrm{mM}$ fructose, $\mathrm{pH}$ 5.7] or $\mathrm{KB}$ liquid media containing the appropriate antibiotics at an optical density at $600 \mathrm{~nm}\left(\mathrm{OD}_{600}\right)$ of 0.4 and 0.1 , respectively. Bacterial cultures were grown at $28^{\circ} \mathrm{C}$ for $16 \mathrm{~h}$ of shaking at 
$220 \mathrm{rpm}$, and the $\mathrm{OD}_{600}$ was adjusted to a final concentration of 0.5 . Bacterial culture $(1 \mathrm{ml}$ of each) was washed with water and was centrifuged. Bacterial pellets were resuspended in $100 \mu \mathrm{l}$ of Laemmli buffer $(20 \mathrm{mM}$ Tris, $1 \%$ sodium dodecyl sulfate [SDS], $0.05 \%$ bromphenol blue, and $10 \%$ glycerol, $\mathrm{pH} 6.8$ ), were boiled for $5 \mathrm{~min}$, and $5 \mu \mathrm{l}$ of each was used for immunoblot analysis. To detect AvrRpt 2 proteins, membranes were probed with $\propto$-hemagglutinin antibody (Roche) conjugated with horseradish peroxidase (HRP).

\section{Agrobacterium-mediated transient protein expression in leaves.}

Agrobacterium tumefaciens 1D1249 (Wroblewski et al. 2005 ) harboring the various expression vectors was grown on LB media with the appropriate antibiotics for 2 days at $30^{\circ} \mathrm{C}$. Bacteria were scraped from the plate, were resuspended in infiltration buffer $(10 \mathrm{mM} \mathrm{MgCl}, 10 \mathrm{mM}$ morpholineethane sulfonic acid [pH 5.6], and $200 \mathrm{mM}$ acetosyringone), and were maintained for $4 \mathrm{~h}$ in the dark at room temperature on a nutator rocker. Bacterial cultures were then washed and centrifuged, and the pellet was resuspended in fresh infiltration buffer before diluting cultures at a final $\mathrm{OD}_{600}$ of 0.15 . Tomato or $N$. benthamiana leaves were infiltrated using a needle-less syringe and were placed in a growth chamber $\left(24^{\circ} \mathrm{C}\right.$ day and $22^{\circ} \mathrm{C}$ night). Leaf samples for protein expression were taken $32 \mathrm{~h}$ later.

\section{Immunoblot detection of plant-expressed proteins.}

Protein samples were analyzed by grinding three leaf disks (9 $\mathrm{mm}$ in diameter) in protein sample buffer $(50 \mathrm{mM}$ Tris $\mathrm{HCl}$ [pH 7.5], 10\% glycerol, 2\% SDS, 2 mM EDTA, $1 \mathrm{mM}$ dithiothreitol, and $1 \%$ protease inhibitor [Sigma-Aldrich]). Samples were separated by SDS-polyacrylamide gel electrophoresis on 4 to $20 \%$ gradient polyacrylamide gels and were transferred to Immobilon-P polyvinylidene diflouride membranes (Millipore), according to standard procedures (Taylor 2015). To detect AvrRpt 2 proteins, membranes were probed with $\propto$-c-Myc (GeneScript) antibody conjugated with HRP. For tomato Rin4 detection, AtRin4 polyclonal antiserum (gift from G. Coaker, University of California Davis) was used at a concentration of 1:2,000. Secondary goat antirabbit immunoglobulin $\mathrm{G}$ conjugated with HRP was used at a dilution of $1: 10,000$ (Promega).

\section{R. pseudosolanacearum disease assays.}

For survival assays with $R$. pseudosolanacearum CMR15, 4-week-old tomato plants (grown in peat pots) were transferred in potting mixture in 3-liter pots to the Toulouse PlantMicrobe Phenotyping facility $\left(28^{\circ} \mathrm{C}, 16 \mathrm{~h}\right.$ of light $)$. Each tomato plant was soil drench-inoculated with $50 \mathrm{ml}$ of $10^{8} \mathrm{CFU}$ per milliliter. Disease scoring was performed daily, using a visual index in which the numbers 1,2,3, and 4 corresponded to $25,50,75$, and $100 \%$ wilted leaves, respectively. Disease scores were transformed into binary data for the purpose of statistical comparison between disease curves (Remigi et al. 2011).

\section{Tomato genome sequencing.}

Genomic DNA was extracted from a single LA4245-R plant using a DNeasy plant mini kit (Qiagen). DNA was mechanically sheared, using the Covaris $\mathrm{S} 2$ adaptative focused acoustic disruptor (Covaris, Inc.), to an average size of 500 to $600 \mathrm{bp}$ and was used to prepare a library. Single-end 100-bp DNA reads were sequenced using the Illumina HiSeq 2000 platform. The reads from LA4245-R were mapped to the S. lycopersicum Heinz 1706 genome sequence SL2.50 (Tomato Genome Consortium 2012) using hisat2 version 2.1.0 (Kim et al. 2015), and single nucleotide polymorphisms (SNPs) were called using GATK version 4.0. (McKenna et al. 2010). SNPs were plotted in 10-kb bins using R. Synteny between SL2.50 and LA2951 version 0.6 was determined using SynMap at CoGe. Protein similarity for RPS2 and MR5 were calculated with Geneious $\mathrm{R} 1$. The genome sequence of LA4245 is available at the National Center for Biotechnology Information Sequence Read Archive under BioProject ID PRJNA516877. The genome sequence of LA2951 is available in the Sol Genomics Network database.

\section{ACKNOWLEDGMENTS}

We thank R. Roberts and A. Collmer for helpful comments on the manuscript, J. Lee for the AvrRpt2 homologs, B. Kunkel for JL1065 strains, G. Coaker for anti-RIN4 antibodies, D. Klessig for A. thaliana rps 2 seeds, K. Munkvold and F. Meng for generating DC3000 strains with T1 effectors, and R. Chetelat and the Tomato Genetics Resource Center for seeds of LA4245. The Ralstonia assays were performed at the Toulouse Plant-Microbe Phenotyping facility of the LIPM-UMR (INRA441/CNRS2594).

\section{LITERATURE CITED}

Alikhan, N. F., Petty, N. K., Ben Zakour, N. L., and Beatson, S. A. 2011. BLAST ring image generator (BRIG): Simple prokaryote genome comparisons. BMC Genomics 12:402.

Almeida, N. F., Yan, S., Lindeberg, M., Studholme, D. J., Schneider, D. J., Condon, B., Liu, H., Viana, C. J., Warren, A., Evans, C., Kemen, E., Maclean, D., Angot, A., Martin, G. B., Jones, J. D., Collmer, A., Setubal, J. C., and Vinatzer, B. A. 2009. A draft genome sequence of Pseudomonas syringae pv. tomato $\mathrm{T} 1$ reveals a type III effector repertoire significantly divergent from that of Pseudomonas syringae pv. tomato DC3000. Mol. Plant-Microbe Interact. 22:52-62.

Ashfield, T., Ong, L. E., Nobuta, K., Schneider, C. M., and Innes, R. W. 2004. Convergent evolution of disease resistance gene specificity in two flowering plant families. Plant Cell 16:309-318.

Axtell, M. J., Chisholm, S. T., Dahlbeck, D., and Staskawicz, B. J. 2003. Genetic and molecular evidence that the Pseudomonas syringae type III effector protein AvrRpt2 is a cysteine protease. Mol. Microbiol. 49: 1537-1546.

Axtell, M. J., McNellis, T. W., Mudgett, M. B., Hsu, C. S., and Staskawicz, B. J. 2001. Mutational analysis of the Arabidopsis RPS2 disease resistance gene and the corresponding pseudomonas syringae avrRpt2 avirulence gene. Mol. Plant-Microbe Interact. 14:181-188.

Bao, Z., Meng, F., Strickler, S. R., Dunham, D. M., Munkvold, K. R., and Martin, G. B. 2015. Identification of a candidate gene in Solanum habrochaites for resistance to a race 1 strain of Pseudomonas syringae pv. tomato. Plant Genome 8.

Bolger, A. M., Lohse, M., and Usadel, B. 2014. Trimmomatic: A flexible trimmer for Illumina sequence data. Bioinformatics 30:2114-2120.

Bombarely, A., Rosli, H. G., Vrebalov, J., Moffett, P., Mueller, L. A., and Martin, G. B. 2012. A draft genome sequence of Nicotiana benthamiana to enhance molecular plant-microbe biology research. Mol. PlantMicrobe Interact. 25:1523-1530.

Buell, C. R., Joardar, V., Lindeberg, M., Selengut, J., Paulsen, I. T., Gwinn, M. L., Dodson, R. J., Deboy, R. T., Durkin, A. S., Kolonay, J. F., Madupu, R., Daugherty, S., Brinkac, L., Beanan, M. J., Haft, D. H., Nelson, W. C., Davidsen, T., Zafar, N., Zhou, L., Liu, J., Yuan, Q., Khouri, H., Fedorova, N., Tran, B., Russell, D., Berry, K., Utterback, T., Van Aken, S. E. Feldblyum, T. V., D’Ascenzo, M., Deng, W. L., Ramos, A. R., Alfano, J. R., Cartinhour, S., Chatterjee, A. K., Delaney, T. P., Lazarowitz, S. G., Martin, G. B., Schneider, D. J., Tang, X., Bender, C. L., White, O., Fraser, C. M., and Collmer, A. 2003. The complete genome sequence of the Arabidopsis and tomato pathogen Pseudomonas syringae pv. tomato DC3000. Proc. Natl. Acad. Sci. U.S.A. 100:10181-10186.

Büttner, D. 2016. Behind the lines-actions of bacterial type III effector proteins in plant cells. FEMS Microbiol. Rev. 40:894-937.

Canady, M. A., Ji, Y., and Chetelat, R. T. 2006. Homeologous recombination in Solanum lycopersicoides introgression lines of cultivated tomato. Genetics 174:1775-1788.

Canady, M. A., Meglic, V., and Chetelat, R. T. 2005. A library of Solanum lycopersicoides introgression lines in cultivated tomato. Genome 48: 685-697.

Carter, M. E., Helm, M., Chapman, A., Wan, E., Restrepo Sierra, A. M., Innes, R., Bogdanove, A. J., and Wise, R. P. 2019. Convergent evolution 
of effector protease recognition by Arabidopsis and barley. Mol. PlantMicrobe Interact. 32:550-565.

Chisholm, S. T., Dahlbeck, D., Krishnamurthy, N., Day, B., Sjolander, K., and Staskawicz, B. J. 2005. Molecular characterization of proteolytic cleavage sites of the Pseudomonas syringae effector AvrRpt2. Proc. Natl. Acad. Sci. U.S.A. 102:2087-2092.

Dangl, J. L., Horvath, D. M., and Staskawicz, B. J. 2013. Pivoting the plant immune system from dissection to deployment. Science 341:746-751.

Day, B., Dahlbeck, D., Huang, J., Chisholm, S. T., Li, D., and Staskawicz, B. J. 2005. Molecular basis for the RIN4 negative regulation of RPS2 disease resistance. Plant Cell 17:1292-1305.

Eschen-Lippold, L., Jiang, X., Elmore, J. M., Mackey, D., Shan, L., Coaker, G., Scheel, D., and Lee, J. 2016. Bacterial AvrRpt2-like cysteine proteases block activation of the Arabidopsis mitogen-activated protein kinases, MPK4 and MPK11. Plant Physiol. 171:2223-2238.

Fahrentrapp, J., Broggini, G. A. L., Kellerhals, M., Peil, A., Richter, K., Zini, E., and Gessler, C. 2012. A candidate gene for fire blight resistance in Malus $\times$ robusta 5 is coding for a CC-NBS-LRR. Tree Genet. Genomes 9:237-251.

Grandillo, S., Chetelat, R. T., Knapp, S., Spooner, D., Peralta, I., Cammareri, M., Perez, O., Termolino, P., Tripodi, P., Chiusano, M. L., Ercolano, M. R., Frusciante, L., Monti, L., and Pignone, D. 2011. Solanum sect. Lycopersicon. Pages 129-215 in: Wild Crop Relatives: Genomics and Breeding Resources, Vegetables. C. Kole, ed. Springer-Verlag, Berlin.

Hassan, J. A., Zhou, Y. J., and Lewis, J. D. 2017. A rapid seedling resistance assay identifies wild tomato lines that are resistant to Pseudomonas syringae pv. tomato race 1. Mol. Plant-Microbe Interact. 30:701-709.

Huet, G. 2014. Breeding for resistances to Ralstonia solanacearum. Front. Plant Sci. 5:715

Jin, P., Wood, M. D., Wu, Y., Xie, Z., and Katagiri, F. 2003. Cleavage of the Pseudomonas syringae type III effector AvrRpt2 requires a host factor(s) common among eukaryotes and is important for AvrRpt2 localization in the host cell. Plant Physiol. 133:1072-1082.

Jones, J. D., and Dangl, J. L. 2006. The plant immune system. Nature 444: 323-329.

Jones, L. A., Saha, S., Collmer, A., Smart, C. D., and Lindeberg, M. 2015. Genome-assisted development of a diagnostic protocol for distinguishing high virulence Pseudomonas syringae pv. tomato strains. Plant Dis. 99:527-534

Kessens, R., Ashfield, T., Kim, S. H., and Innes, R. W. 2014. Determining the GmRIN4 requirements of the soybean disease resistance proteins $\mathrm{Rpg} 1 \mathrm{~b}$ and Rpg1r using a nicotiana glutinosa-based agroinfiltration system. PLoS One 9:e108159.

Kim, D., Langmead, B., and Salzberg, S. L. 2015. HISAT: A fast spliced aligner with low memory requirements. Nat. Methods 12:357-360.

King, E. O., Ward, M. K., and Raney, D. E. 1954. Two simple media for the demonstration of pyocyanin and fluorescin. J. Lab. Clin. Med. 44:301-307.

Koren, S., Walenz, B. P., Berlin, K., Miller, J. R., Bergman, N. H., and Phillippy, A. M. 2017. Canu: Scalable and accurate long-read assembly via adaptive $k$-mer weighting and repeat separation. Genome Res. 27: 722-736.

Kraus, C. M., Mazo-Molina, C., Smart, C. D., and Martin, G. B. 2017. Pseudomonas syringae pv. tomato strains from New York exhibit virulence attributes intermediate between typical race 0 and race 1 strains. Plant Dis. 101:1442-1448.

Kunkeaw, S., Tan, S., and Coaker, G. 2010. Molecular and evolutionary analyses of Pseudomonas syringae pv. tomato race 1. Mol. PlantMicrobe Interact. 23:415-424.

Kvitko, B. H., and Collmer, A. 2011. Construction of Pseudomonas syringae pv. tomato DC3000 mutant and polymutant strains. Methods Mol. Biol. 712:109-128.

Lim, M. T., and Kunkel, B. N. 2004a. The Pseudomonas syringae type III effector AvrRpt 2 promotes virulence independently of RIN4, a predicted virulence target in Arabidopsis thaliana. Plant J. 40:790-798.

Lim, M. T., and Kunkel, B. N. 2004b. Mutations in the Pseudomonas syringae avrRpt 2 gene that dissociate its virulence and avirulence activities lead to decreased efficiency in AvrRpt2-induced disappearance of RIN4. Mol. Plant-Microbe Interact. 17:313-321.

Lim, M. T., and Kunkel, B. N. 2005. The Pseudomonas syringae avrRpt2 gene contributes to virulence on tomato. Mol. Plant-Microbe Interact. 18:626-633

Lin, N. C., Abramovitch, R. B., Kim, Y. J., and Martin, G. B. 2006. Diverse AvrPtoB homologs from several Pseudomonas syringae pathovars elicit Pto-dependent resistance and have similar virulence activities. Appl. Environ. Microbiol. 72:702-712.

Mackey, D., Belkhadir, Y., Alonso, J. M., Ecker, J. R., and Dangl, J. L. 2003. Arabidopsis RIN4 is a target of the type III virulence effector AvrRpt2 and modulates RPS2-mediated resistance. Cell 112:379-389.
Mahbou Somo Toukam, G., Cellier, G., Wicker, E., Guilbaud, C., Kahane, R., Allen, C., and Prior, P. 2009. Broad diversity of Ralstonia solanacearum strains in Cameroon. Plant Dis. 93:1123-1130.

McKenna, A., Hanna, M., Banks, E., Sivachenko, A., Cibulskis, K., Kernytsky, A., Garimella, K., Altshuler, D., Gabriel, S., Daly, M., and DePristo, M. A. 2010. The genome analysis toolkit: A MapReduce framework for analyzing next-generation DNA sequencing data. Genome Res. 20:1297-1303.

Meyer, F., Paarmann, D., D’Souza, M., Olson, R., Glass, E. M., Kubal, M., Paczian, T., Rodriguez, A., Stevens, R., Wilke, A., Wilkening, J., and Edwards, R. A. 2008. The metagenomics RAST server-A public resource for the automatic phylogenetic and functional analysis of metagenomes. BMC Bioinformatics 9:386.

Oh, H. S., Kvitko, B. H., Morello, J. E., and Collmer, A. 2007. Pseudomonas syringae lytic transglycosylases coregulated with the type III secretion system contribute to the translocation of effector proteins into plant cells. J. Bacteriol. 189:8277-8289.

Pedley, K. F., and Martin, G. B. 2003. Molecular basis of Pto-mediated resistance to bacterial speck disease in tomato. Annu. Rev. Phytopathol. 41:215-243.

Peeters, N., Carrère, S., Anisimova, M., Plener, L., Cazalé, A. C., and Genin, S. 2013. Repertoire, unified nomenclature and evolution of the type III effector gene set in the Ralstonia solanacearum species complex. BMC Genomics 14:859.

Peralta, I. E., Spooner, D. M., and Knapp, S. 2008. Taxonomy of wild tomatoes and their relatives (Solanum sect. Lycopersicoides, sect. Juglandia, sect. Lycopersicon; Solanaceae). American Society of Plant Taxonomists, Laramie, WY, U.S.A..

Pitblado, R. E., and Kerr, E. A. 1980. Resistance to bacterial speck (Pseudomonas tomato) in tomato. Acta Hortic.: 379-382.

Remenant, B., Coupat-Goutaland, B., Guidot, A., Cellier, G., Wicker, E., Allen, C., Fegan, M., Pruvost, O., Elbaz, M., Calteau, A., Salvignol, G., Mornico, D., Mangenot, S., Barbe, V., Médigue, C., and Prior, P. 2010. Genomes of three tomato pathogens within the Ralstonia solanacearum species complex reveal significant evolutionary divergence. BMC Genomics 11:379.

Remigi, P., Anisimova, M., Guidot, A., Genin, S., and Peeters, N. 2011. Functional diversification of the GALA type III effector family contributes to Ralstonia solanacearum adaptation on different plant hosts. New Phytol. 192:976-987.

Saha, S., and Lindeberg, M. 2013. Bound to succeed: Transcription factor binding-site prediction and its contribution to understanding virulence and environmental adaptation in bacterial plant pathogens. Mol. PlantMicrobe Interact. 26:1123-1130.

Salmeron, J. M., Oldroyd, G. E., Rommens, C. M., Scofield, S. R., Kim, H. S., Lavelle, D. T., Dahlbeck, D., and Staskawicz, B. J. 1996. Tomato Prf is a member of the leucine-rich repeat class of plant disease resistance genes and lies embedded within the Pto kinase gene cluster. Cell 86:123-133.

Seemann, T. 2014. Prokka: Rapid prokaryotic genome annotation. Bioinformatics 30:2068-2069.

Selote, D., and Kachroo, A. 2010. RPG1-B-derived resistance to AvrBexpressing Pseudomonas syringae requires RIN4-like proteins in soybean. Plant Physiol. 153:1199-1211.

Taylor, S. N. 2015. Using antibodies: A laboratory manual. Q. Rev. Biol. 74:267-311.

Thapa, S. P., Miyao, E. M., Michael Davis, R., and Coaker, G. 2015. Identification of QTLs controlling resistance to Pseudomonas syringae pv. tomato race 1 strains from the wild tomato, Solanum habrochaites LA1777. Theor. Appl. Genet. 128:681-692.

Tomato Genome Consortium. 2012. The tomato genome sequence provides insights into fleshy fruit evolution. Nature 485:635-641.

Tornero, P., and Dangl, J. L. 2002. A high-throughput method for quantifying growth of phytopathogenic bacteria in Arabidopsis thaliana. Plant J. 28:475-481.

Toruño, T.Y., Shen, M., Coaker, G., and Mackey, D. 2019. Regulated disorder: Posttranslational modifications control the RIN4 plant immune signaling hub. Mol. Plant-Microbe Interact. 32:45-55. .

Vogt, I., Wöhner, T., Richter, K., Flachowsky, H., Sundin, G. W., Wensing, A., Savory, E. A., Geider, K., Day, B., Hanke, M. V., and Peil, A. 2013. Gene-for-gene relationship in the host-pathogen system Malus $\times$ robusta 5-Erwinia amylovora. New Phytol. 197:1262-1275.

Walker, B. J., Abeel, T., Shea, T., Priest, M., Abouelliel, A., Sakthikumar, S., Cuomo, C. A., Zeng, Q., Wortman, J., Young, S. K., and Earl, A. M. 2014. Pilon: An integrated tool for comprehensive microbial variant detection and genome assembly improvement. PLoS One 9:e112963.

Whalen, M. C., Innes, R. W., Bent, A. F., and Staskawicz, B. J. 1991. Identification of Pseudomonas syringae pathogens of Arabidopsis and a bacterial locus determining avirulence on both Arabidopsis and soybean. Plant Cell 3:49-59. 
Wroblewski, T., Tomczak, A., and Michelmore, R. 2005. Optimization of Agrobacterium-mediated transient assays of gene expression in lettuce, tomato and Arabidopsis. Plant Biotechnol. J. 3:259-273.

Yan, S., Liu, H., Mohr, T. J., Jenrette, J., Chiodini, R., Zaccardelli, M., Setubal, J. C., and Vinatzer, B. A. 2008. Role of recombination in the evolution of the model plant pathogen Pseudomonas syringae pv. tomato DC3000, a very atypical tomato strain. Appl. Environ. Microbiol. 74:3171-3181.

Zhao, Y., He, S. Y., and Sundin, G. W. 2006. The Erwinia amylovora avrRpt2EA gene contributes to virulence on pear and AvrRpt2EA is recognized by Arabidopsis RPS2 when expressed in Pseudomonas syringae. Mol. Plant-Microbe Interact. 19:644-654.

\section{AUTHOR-RECOMMENDED INTERNET RESOURCES}

CoGe database: https://genomevolution.org/coge/SynMap.pl Geneious R11: https://www.geneious.com

LIPM Ralsto T3E database:

https://iant.toulouse.inra.fr//bacteria/annotation/site/prj/T3Ev3

PacBio Arrow software: https://github.com/PacificBiosciences/pbbioconda Sol Genomics Network:

https://solgenomics.net/organism/Solanum_lycopersicoides/genome Tomato Genetics Resource Center:

https://tgrc.ucdavis.edu/lycopersicoides_ils.aspx 